\title{
Editorial
}

\section{Cristianismo primitivo na cidade: conflitos e resistências}

ILDO PERONDI

VICENTE ARTUSO

WALDIR SOUZA

O grupo dos seguidores e seguidoras de Jesus na Palestina se expandiu no primeiro século, chegando aos grandes centros urbanos do Império Romano: Filipos, Tessalônica, Corinto, Atenas, Éfeso, Roma, entre outros. Posteriormente em Antioquia eles passaram a ser chamados "cristãos" (At 11,26). A partir da diáspora, podemos falar de cristianismos originários no final do primeiro século, quando novas comunidades surgiram e se organizaram em contextos diferentes. Podemos afirmar que o fio condutor para qualquer história do cristianismo primitivo foi a irresistível expansão da fé cristã na região do Mediterrâneo durante os primeiros cento e vinte anos. Paulo viajou cerca de dez mil milhas, segundo estudos nos Atos dos Apóstolos (MEEKS, 1992, p. 32).

O tema desse dossiê destaca as características do movimento de Jesus, com novas configurações, na passagem do contexto rural da Galileia para os grandes centros urbanos. Encontramos informações a partir dos documentos mais antigos: Cartas do apóstolo Paulo, Evangelhos, Atos dos Apóstolos e

\footnotetext{
a Pontifícia Universidade Católica do Paraná (PUCPR), Curitiba, PR, Brasil. Doutor em Teologia Bíblica, e-mail: ildo.perondi@pucpr.br

b Pontifícia Universidade Católica do Paraná (PUCPR), Curitiba, PR, Brasil. Doutor em Teologia Bíblica, e-mail: vicente.artuso@pucpr.br

c Pontifícia Universidade Católica do Paraná (PUCPR), Curitiba, PR, Brasil. Doutor em Teologia, e-mail:waldir.souza@pucpr.br
} 
outros escritos do Novo Testamento. Se a origem do cristianismo teve lugar na sinagoga como um prolongamento do judaísmo da diáspora, seu desenvolvimento e lenta institucionalização não ocorreu sem conflitos internos e com o "status quo" do Império. Com efeito, ao considerar-se uma extensão do judaísmo, os seguidores e seguidoras de Jesus obtinham certa legitimidade e cidadania. Porém, ao desligar-se das sinagogas o novo grupo passou a ser descrito como reacionário e considerado, por autores antigos, uma "seita perniciosa".

Não faltaram os conflitos e divisões entre grupos, por motivos culturais, religiosos, doutrinários de tendências diversas, representadas por diferentes grupos, de Paulo, Cefas, Apolo (1Cor 1,12). O esforço em buscar a unidade já no início aparece na parênese paulina adotada de um antigo credo batismal: “Todos vós que fostes batizados em Cristo, vos revestistes de Cristo. Não há judeu nem grego, nem escravo nem livre, nem homem nem mulher. Todos vós sois um só em Cristo Jesus" (GI 3,27-28). Paulo reforça a unidade em Cristo. Tornar-se filhos de Deus em Cristo significava romper as barreiras sociais e étnicas em vista da unidade (cf. CORSANI, 1990, p. 243).

A grande cidade, com enormes desníveis sociais e variedade de experiências religiosas é o campo desafiador da missão. Era necessário adaptar-se a novas situações. O apóstolo Paulo, quando chegou em Corinto, sendo cidadão livre, modificou sua condição de vida e assumiu a condição de servo, trabalhando com as próprias mãos para ganhar seu sustento e pregar gratuitamente o Evangelho. O trabalho manual foi a porta de entrada na vida do povo da periferia (MESTERS, 1991, p. 56-59). Narram os Atos dos Apóstolos que ele se dirigia primeiro à sinagoga no sábado, e ali pregava aos judeus e gentios, partindo das Escrituras. Sozinho pouco poderia fazer; era importante estender as mãos aos companheiros colunas da Igreja, Pedro, Tiago e João, da Igreja mãe em Jerusalém (Gl 2). No mundo grego, Paulo contou com numerosos colaboradores e colaboradoras, no início: Barnabé, Marcos, Silvano, Timóteo, Aquila, Priscila e tantos outros; são cerca de 150 nomes citados nas cartas. Se não conseguia grandes resultados na pregação na sinagoga, obteve no contato com pequenos grupos, reunidos nas casas. A chamada Igreja doméstica tornara-se então uma realidade, lugar de comunhão e celebração da eucaristia dos cristãos. Convém destacar que o apóstolo 
investiu num movimento de renovação contra a hegemonia romana nos grandes centros urbanos. A proposta de comunidades eclesiais cristãs se apresentava como alternativa para populações mais pobres do império, uma proposta de novas relações que minavam as bases do poder imperial (DA SILVA, 2018).

Eis uma breve amostra dos inícios do cristianismo que aos poucos se organizou e se consolidou em grandes centros urbanos, e alguns deles posteriormente formaram os patriarcados: Jerusalém, Antioquia, Alexandria e Constantinopla. Roma se tornaria o centro da unidade e então o catolicismo ganhou status de religião com proteção imperial. Mais tarde, surgiram movimentos de oposição firme para libertar-se das amarras do poder do Estado e voltar às origens genuínas do Evangelho. Conflitos e divisões durante séculos perduraram. No entanto, na história surgiram também personagens que foram profetas de novos tempos, luminares retomando as fontes.

A história então revela avanços e retrocessos. Poucas são as informações encontradas em escritores antigos sobre Jesus e seu movimento. Porém, o testemunho escrito no Novo Testamento, ainda que idealizado, oferece um quadro bem caracterizado do cristianismo primitivo. Aprendemos com a memória dos fatos, também, a reinterpretar e reinventar novos métodos de evangelização no contexto atual.

As contribuições dos autores nesse dossiê nos situam no contexto das origens ao mesmo tempo que alargam os horizontes teológicos à luz dos desafios da Igreja atual.

No primeiro artigo, Fabrizio Zandonadi Catenassi e Ildo Perondi refletem como Jesus iniciou o anúncio do Reino de Deus nas cidades, a partir da análise de LC 4,42-44. O Jesus que Lucas apresenta em seu Evangelho é aquele que caminha e se desloca por cidades e povoados. Sua palavra é acompanhada de grandes sinais, mostrando sua autoridade ao tornar real o projeto que havia sido proclamado na sinagoga de Nazaré. Com isso, é possível identificar os traços da missão de Jesus que se manifestam em seu anúncio: "Também para outras cidades é necessário que eu anuncie o Reino de Deus, porque para isso fui enviado" (Lc 4,43). Jerusalém é a cidade central na história salvífica, a cidade dos eventos pascais e da revelação do senhorio do Ressuscitado. Todo o Evangelho converge para Jerusalém e é dessa cidade que a mensagem parte 
em direção aos confins do mundo. Assim, o Evangelho de Lucas ilumina a proposta do Papa Francisco, que quer uma Igreja "em saída”.

Isidoro Mazzarolo demonstra como o discurso de Paulo no areópago de Atenas (At 17,22-34) estabelece um paradigma muito claro no que concerne à prática evangelizadora e aos desafios dos cristãos nas primeiras décadas. Os pagãos estavam muito abertos a novidades religiosas; não só filósofos estoicos e epicureus, mas de outras correntes de pensamento sempre estavam atentos para novas teorias e realidades. Paulo aproveita o espírito de religiosidade dos pagãos para fazer a sua proposta de identificação do Deus desconhecido.

$\mathrm{Na}$ Carta aos Filipenses, Paulo menciona o conflito entre Evódia e Síntique (FI 4,2), o que se torna um antagonismo à comunidade ideal e que deve ser superado. Waldecir Gonzaga e Vilson da Silva constatam que é incomum encontrar uma comunidade eclesial que não tenha experimentado ou esteja experimentando problemas internos ou conflitos acirrados entre seus membros e que afetam e desagregam a vida da comunidade. Os autores enfatizam que desde os primórdios da Igreja, os conflitos estão presentes no seu interior e que não é certo romantizar, de modo ingênuo, a vivência das primeiras comunidades a ponto de achar que lá, não houvesse conflitos ou que tudo corria às "mil maravilhas", mas de compreender, à luz destes acontecimentos, as comunidades e as relações de conflitos, que se estabelecem também no hoje da história e, tomando como referência a perícope de $\mathrm{Fl}$ 4,1-7, evidenciar como o apóstolo lidou com esta situação e quais foram as luzes jogadas sobre o problema e suas possíveis soluções.

Boris Agustin Nef Ulloa e Jean Richard Lopes evidenciam as raízes da identidade cristã e suas consequências para uma comunidade exposta num ambiente adverso à vivência da fé, presentes na Primeira Carta de Pedro. O artigo é composto por duas partes; a primeira, numa perspectiva introdutória, contextualiza a realidade concreta da referida comunidade a partir de quatro elementos: matriz cultural, geografia, ambiente social e situação histórica. A segunda parte, oferece uma leitura teológica com ênfase em quatro pontos: eleição, cristologia, escatologia e testemunho. O percurso realizado permite observar quão importante é resgatar suas raízes identitárias para uma comunidade cristã que, imersa num contexto social hostil, vive a experiência 
de ser minoria. Esta realidade desafiadora, longe de ser uma experiência perdida, permite-lhe crescer na consciência da eleição e na vivência de um testemunho missionário humilde e autêntico.

Sidney Damasio Machado analisa a expressão "manifestado na carne" $(1 \mathrm{Tm} 3,16)$ na transmissão da mensagem cristã na Igreja primitiva. O tema da epifania/visão unifica a maior parte das expressões religiosas e filosóficas no mundo greco-romano do começo da nossa era. O uso da expressão "manifestado na carne" nas Cartas Pastorais é indicativo dos esforços do cristianismo primitivo para dialogar com a cultura e inculturar o conteúdo da fé cristã no ambiente helenista. Constatar o empenho por uma evangelização inculturada na Igreja primitiva se constitui como estímulo e provocação em vista de uma evangelização inculturada.

Uma importante contribuição sobre as visitas de Deus ao seu povo presentes nas Sagradas Escrituras é apresentada por Vicente Artuso e Patrícia Zaganin Camilo Rosa. As visitas são caracterizadas como eventos em que Deus intervém para trazer benefícios ou também juízo e punição. Os autores analisam o verbo "visitar", no hebraico paqad, e o seu correspondente grego episkeptomai no Novo Testamento. A fidelidade ou infidelidade do povo determina a ação de Deus como juiz que visita seu povo para socorrer e salvar, ou para punir e castigar. Partem de textos proféticos de Juízo sobre Jerusalém, para destacar no Novo Testamento a salvação pela visita de Deus que é reconhecida nas ações benéficas que Jesus realiza. Porém, Jesus se tornou também sinal de contradição para os que o rejeitam, atraindo o juízo. Assim o artigo mostra os conflitos e resistências diante da visita salvadora de Jesus. Finalmente o estudo conclui com a hermenêutica pastoral da cidade, destacando a necessidade de rever a práxis pastoral urbana em tempos de pandemia.

Na sequência, Carlos Alberto Motta Cunha e Junior Vasconcelos do Amaral refletem sobre a Pastoral Urbana: o “ver" decolonial de Jesus. Apresentam um questionamento: como o ministério de Jesus Cristo, descrito nos Evangelhos, pode inspirar e desafiar a teologia pastoral de hoje? E oferecem respostas inconclusas a esta questão, apontando para uma pastoral cristã no contexto urbano contemporâneo. O mundo da cidade, dinâmico e plural, interpela a prática pastoral capaz de "ver" com profundidade os seus dilemas e dar uma 
palavra prática e libertadora às pessoas que lutam pela sobrevivência. Inspirados pelo caminho do próprio Cristo, analisam exegeticamente pequenas narrativas do "ver de Jesus" à luz do pensamento decolonial como provocações para a pastoral urbana. Sem medo de cair em anacronismos, constatam a importância das ações subversivas de Jesus capazes de romper as amarras colonialistas e promover a decolonialidade dos corpos e das convicções.

Uma importante contribuição diante da realidade atual é oferecida por Claudio Antônio Delfino, Donizete José Xavier e Jerusa Lisboa Pacheco Reis ao analisar o cristianismo, a sociedade brasileira e a violência doméstica, com suas faces desfiguradas e seus gritos de socorro. É dos dramas da pandemia do novo Coronavírus que surge o vazio, o choro e as lágrimas de milhares de famílias enlutadas pela morte de seus entes queridos. O isolamento social fez aumentar a violência doméstica e emergir os gritos de socorro dessas tantas vozes abafadas. Os autores se propõem verificar quais seriam os desafios atuais, especificamente para o cristianismo e para a Sociedade Brasileira, no combate à violência doméstica e como tornarem-se próximos dos que já são acometidos por tão grandes sofrimentos e tomar atitudes que previnam futuros horrores. Diante deste quadro levantam duas questões necessárias: É legítima a prática de um modelo religioso cristão, tendo Jesus Cristo como fundamento, que se baseie na premissa da situação individual daqueles que estão bem sem se importar como está a situação dos demais irmãos e irmãs? É possível para qualquer pessoa de boa vontade e para uma sociedade inteira negligenciarem-se diante da desfiguração dos rostos e dos gritos de sofrimento de milhares de crianças, adolescentes e mulheres?

Nestes tempos de tanta correria e muito trabalho, Haroldo e Ivoni Richter Reimer nos brindam com uma interessante reflexão sobre a heterotopia dos tempos de pausa na Bíblia, a partir de alguns textos bíblicos que sugerem a observância de tempos de pausa, com a análise de fragmentos textuais que se originaram ao longo dos tempos e propõem a heterotopia para que em meio ao curso normal das jornadas de trabalho e de tempo houvesse tempos de pausa. São as tradições sabáticas que se referem ao dia sábado como dia de descanso, ao ano sabático para descanso da terra e para o livre acesso aos frutos pelos pobres e pelos animais, bem como de perdão de 
dívidas. Na boca de Jesus de Nazaré, esta tradição ganhou a defesa mais contundente e mais conhecida, afirmando que o dia de sábado deve estar em função das pessoas e não o contrário. Nas tradições judaica e cristã trata-se de uma radical defesa do necessário cuidado com a vida, que deveria ser assumida como heterotopia também em termos de espiritualidade.

\section{Fluxo contínuo}

Abrimos o Fluxo Contínuo com um importante artigo do teólogo biblista suíço Konrad Schmid, traduzido por Luís Marcos Sanders, sobre a composição da Bíblia a partir dos primeiros fragmentos. A Sagrada Escritura é uma obra de escribas, em geral anônimos, escrita no longo período que vai desde o século IX a.C. até o século II d.C., cujas tradições orais se estendem a dois milênios a.C. O resultado é um texto complexo, porém legível, como demonstra sua longa história de recepção, principalmente no judaísmo e no cristianismo. A Bíblia revela um interessante conjunto de pesos e contrapesos entre suas posições teológicas; parece que os autores não se preocuparam sempre com a consistência narrativa, mas, antes, com a criação de um universo literário que inclui uma variedade de perspectivas teológicas.

Neste período em que a sociedade mundial reflete sobre a crise socioambiental, Luiz Alexandre Solano Rossi e Érica Daiane Mauri apresentam uma reflexão sobre a espiritualidade e integridade da criação trazendo-nos uma nova percepção da atitude ecológica do ser humano a partir de Gn 2,15. As respostas à crise socioambiental demandam os esforços de todos os saberes e de todos os seres humanos em busca de possíveis caminhos para superá-la e para resguardar o princípio de vida. Através da abordagem qualitativa e bibliográfica, buscam no texto bíblico elementos que ajudem os seres humanos a promoverem uma nova percepção de suas atitudes ecológicas, a partir da espiritualidade e da integridade da criação.

Allan da Silva Coelho propõe um diálogo entre a Pedagogia do Oprimido de Paulo Freire e as propostas do Papa Francisco na Encíclica Laudato Si'. As reflexões sobre discernimento e educação ecológica indicam um itinerário pedagógico comum entre o Papa Francisco e Paulo Freire. A partir da metodologia dialética goldminiana, o autor defende que a transição ecológica 
da Laudato Si' explicita elementos de uma educação antifetichista (com afinidades aos estudos do "capitalismo como religião"), que permitiriam outros modelos de humanidade.

Na sequência, Francisco Chagas de Albuquerque nos oferece um artigo sobre tradições religiosas: monoteísmos e fraternidade universal. O autor destaca a importância das religiões monoteístas e a possibilidade e necessidade de sua contribuição para que a humanidade desperte e se comprometa com a busca da fraternidade universal. Nos genuínos valores do judaísmo, cristianismo e islamismo existem elementos que levam seus adeptos praticantes a despertarem para o compromisso com a fraternidade entre todos os seres humanos e povos. O ensino social do Papa Francisco é uma contribuição para essa empreitada como sonho lúcido a ser alcançado. A partir de aspectos filosófico-religiosos e antropológico-religioso, identificam-se as religiões como mediações histórico-culturais da relação do ser humano com o Transcendente; as reflexões das encíclicas Laudato si' e Fratelli Tutti são propostas como contributo do cristianismo para construção da fraternidade universal.

Por sua vez, Castor Bartolomé Ruiz e José Mozart Tanajura Júnior apresentam uma reflexão sobre a forma-de-vida do primeiro monasticismo cristão no contexto problematizador entre regra e vida, regula vitae. A partir das pesquisas desenvolvidas por Giorgio Agamben sobre esta temática, analisam de que modo a tensão entre regra-e-vida dos primeiros monacatos cristãos privilegiava a vida como referente constitutivo da regra, e não ao contrário. O artigo analisa como a vida monástica cria sua regra e faz da regra uma forma-de-vida, de tal modo que viver a regra excede qualquer obrigação jurídica, desativando, assim, a força da lei através da vida que vive a regra além das meras obrigações prescritivas da lei. Por fim, o artigo correlaciona a problemática da forma-de-vida do monacato cristão primitivo com o contexto das atuais sociedades de controle em que a vida é capturada massivamente por meio de uma infinidade de dispositivos que governamentalizam os comportamentos dos sujeitos. Os modos de resistência aos atuais dispositivos biopolíticos de controle da vida exigem a capacitação de criar formas-de-vida em que o viver não seja separado da forma. 
Nelson Maria Brechó da Silva e Francisco Marques Miranda Filho apresentam uma aproximação temática do Santuário de Ex 31,1-11: características, contexto histórico, artesãos e beleza, numa abordagem da estética teológica ou teologia estética, evidenciando o belo como ponto de partida e objeto de uma ciência externa. Segundo Von Balthazar, tanto a visão como o êxtase colaboram para refletir a dimensão teológica e estética em três níveis: primeiro, elucidam-se as caraterísticas da construção do Santuário do Deserto (Ex 25-31,11): texto e o contexto de Ex 31,1-11; segundo, apontam-se o santuário e contexto histórico; e, terceiro, descrevem-se acerca dos artesãos, de suas habilidades e da beleza. Diante desse cenário, o resultado a ser alcançado consiste em que a autoria da obra de arte é um ponto conclusivo que merece destaque, porque cada artista é um experto na obra que realiza.

O último artigo deste número é de Edilmar Cardoso Ribeiro, que aborda a opção preferencial pelos pobres em Santa Dulce dos Pobres (1914-1992), que desenvolveu e sustentou um intenso apostolado social de total dedicação aos pobres, deixando um legado que constitui um dos maiores complexos filantrópicos sociais do Brasil. Por meio de um estudo qualitativo e bibliográfico, o trabalho apresenta a opção preferencial pelos pobres de Santa Dulce como uma radical experiência de amor e serviço, de solidariedade e fraternidade para com os mais necessitados; explica como a opção de Santa Dulce ilumina e é estimulada pela opção preferencial pelos pobres do Episcopado Latino Americano na Conferência de Medellín (1968); esclarece como a opção de Santa Dulce se fundamenta no amor a Cristo sofredor, presente no rosto do pobre, o outro Cristo; e, por fim, propõe Santa Dulce como a boa samaritana da Bahia.

Desejamos que mais esta edição da Revista Pistis \& Práxis contribua para a reflexão sobre o cristianismo primitivo na cidade, conflitos e resistências e ilumine as práticas pastorais nestes tempos de crises, mudanças rápidas e que exigem de nós sinais indicativos de esperança e perseverança, como afirma o autor da Primeira Carta de Pedro: "mostrem a todos as razões da vossa esperança" (1Pd 3,15). 


\section{Referências}

CORSANI, B. Lettera ai Galati. Genova: Marietti, 1990.

DA SILVA, V. Paulo, o Império Romano e a Monarquia de Israel. In: FIGUEIREDO, T. J. A.; CATENASSI, F. Z. (Orgs.). Paulo. Contextos e leituras. São Paulo: Paulinas, 2018.

MEEKS, W. A. Os primeiros cristãos urbanos. O mundo social do Apóstolo Paulo. São Paulo: Paulinas, 1992.

MESTERS, C. Paulo um trabalhador que anuncia o Evangelho aos pobres. São Paulo: Paulinas, 1991. 